\title{
Can the lunar crust be magnetized by shock: Experimental groundtruth
}

\author{
J. Gattacceca $^{\text {a,* }}$, M. Boustie $^{\text {b }}$, L. Hood ${ }^{\text {c }}$, J.-P. Cuq-Lelandais ${ }^{\text {b }}$, M. Fuller ${ }^{\text {d }}$, N.S. Bezaeva ${ }^{\text {e, }}$ \\ T. de Resseguier ${ }^{b}$, L. Berthe ${ }^{\mathrm{f}}$ \\ a CEREGE, CNRS/Aix-Marseille University, BP 80, 13545 Aix-en-Provence cedex 4, France \\ b PPRIME, CNRS-ENSMA-Université de Poitiers, 1 avenue Clément Ader, 86961 FUTUROSCOPE, France \\ c Lunar and Planetary Laboratory, University of Arizona, 1629 E. University Blvd, Tucson, Arizona 85721-0092, USA \\ d HIGP-SOEST, POST 716, U. Hawaii Manoa Campus, Honolulu, HI 96822, USA \\ e Earth Physics Dept., Faculty of Physics, M.V. Lomonosov Moscow State University, Leninskie gory 119991 Moscow, Russia \\ f PIMM, CNRS-ENSAM Paristech, 151 Boulevard de l'Hôpital, 75013 Paris, France
}

Keywords:

shock remanent magnetization

lunar paleomagnetism

lunar magnetic anomalies

\begin{abstract}
A B S T R A C T
Since the first evidence of magnetized lunar crust, two mechanisms of magnetization have been suggested to account for lunar magnetism: thermoremanent magnetization (TRM), or shock remanent magnetization (SRM). We present here the first experimental acquisition of shock remanence by lunar rocks in the $0.1-2$ GPa range, and discuss their implications for the interpretation of the paleomagnetic record of these rocks, as well as for the distribution of magnetic anomalies revealed by orbital data. Laser shock experiments in controlled magnetic fields performed on lunar mare basalts demonstrated that in the presence of an ambient field these rocks can be magnetized significantly starting at low pressure $(\sim 0.1 \mathrm{GPa})$. Hydrostatic loading experiments up to $1.8 \mathrm{GPa}$ in controlled magnetic fields were used to impart piezo-remanent magnetization (an analogue for shock remanent magnetization) to mare basalts and highland regolith breccias. These experiments allow quantifying the shock remanence as a function of pressure and ambient field.

Regarding the lunar antipodal magnetic anomaly model, our results show that lunar soils, regolith breccia and about $40 \%$ of lunar highland rocks (comprising regolith and impact-melt breccia) in the upper crust can be magnetized by low pressure shocks ( $<10 \mathrm{GPa}$ ) to sufficient levels to account for the observed lunar antipodal anomalies. Therefore, the antipodal magnetization model appears to be plausible based on our experimental results, provided that several $\mathrm{km}$ of regolith and/or impact-processed rocks can be found at the antipodes of large impact basins.

For typical lunar rocks dominated by multidomain FeNi with low Ni content, the maximum remanent magnetization that can be acquired during a low pressure shock $(<10 \mathrm{GPa})$ is about a third of what is expected for a TRM acquired in the same ambient field. Some mare basalts have identical coercivity spectra for their natural remanent magnetization and their SRM, leaving open the possibility that the NRM was imparted during an impact at the lunar surface. In that case, magnetizing fields of the order of 40 to $95 \mu \mathrm{T}$ are required. SRM acquisition experiments appear necessary to ground the interpretation of lunar paleomagnetism, and should become a standard technique in lunar and extraterrestrial paleomagnetism.
\end{abstract}

\section{Introduction}

Paleomagnetic measurements of returned lunar samples (e.g., Fuller and Cisowski, 1987; Lawrence et al., 2008; Garrick-Bethell et al., 2009), and surface (Dyal et al., 1970) and orbital magnetic field measurements (e.g., Richmond and Hood, 2008; Mitchell et al., 2008) demonstrate that many lunar crustal rocks carry a significant remanent magnetization. The origin of these magnetizations and of the magnetizing fields are presently unresolved. Since the first evidence of magnetized lunar crust, there have been two mainstream

\footnotetext{
* Corresponding author. Tel.: + 334429715 08, fax: + 33442971595 . E-mail address: gattacceca@cerege.fr (J. Gattacceca).
}

theories to account for lunar magnetism (e.g., Collinson, 1993): magnetization by cooling of magmatic rocks below their Curie temperature (thermoremanent magnetization, TRM), or magnetization by shock (shock remanent magnetization, SRM). In both cases, a magnetizing field is required. Thermoremanent magnetization requires a steady magnetic field during cooling through the blocking temperatures of lunar rocks (i.e. on a time scale of at least several days), which implies an internal origin, namely a core dynamo. Conversely, shock magnetization is acquired instantaneously and in that case both steady (internal or external) or transient magnetic fields can account for the magnetizing field. In the case of shock magnetization, transient fields could be impact-produced (Crawford and Schultz, 1988) or, for large impact basins, could result from the compression by the expanding impact plasma of a pre-existing 
magnetic field that could be internal (dynamo generated) or external (solar wind field for instance) (e.g., Hood and Artemieva, 2008).

Understanding the nature of lunar remanent magnetization is therefore fundamental to better constraining the nature of the magnetizing field. In particular, if a TRM origin can be demonstrated for at least some samples and/or orbital anomaly sources, the existence of an ancient core dynamo is indicated (e.g., Garrick-Bethell et al., 2009) with strong implications for the thermal evolution of the Moon. Implications for lunar internal structure would also follow since the existence of a lunar ironrich core, while plausible, remains geophysically unconfirmed (e.g., Wieczorek et al., 2006). On the other hand, if an SRM origin for some samples/sources can be demonstrated, the importance of transient fields is indicated with implications for the interpretation of paleomagnetism on all silicate bodies in the solar system.

Currently, there are indications from orbital data that both SRM and TRM may have played important roles in shaping the lunar magnetic anomalies observed today. In the case of SRM, shocks may have had two antagonistic effects: demagnetizing and magnetizing the lunar crust. Demagnetization is observed up to $\sim 2-4$ crater radii around lunar impact craters (Halekas et al., 2002). It can be attributed to a combination of the excavation process (as proposed on Mars for impact basins by e.g., Langlais et al., 2010), to shock demagnetization (if the ambient field was null during the impact), or to a poorly efficient shock magnetization process that would result, even in the presence of an ambient field, in a lower post-shock magnetization compared to the pre-shock one. However, the largest concentrations of strong magnetic anomalies are observed antipodal to the four largest young basins (Imbrium and Orientale that are Imbrian in age, and Serenitatis and Crisium that are late Nectarian in age) and have been tentatively explained by shock magnetization. The mechanism invoked to explain these strong anomalies is shock magnetization of impact-processed materials located at the antipode to the large basins. In such a model, the shock waves would be generated by antipodal focusing of the main shock wave and/or the occurrence of simultaneous secondary impact shock waves, and a strong magnetizing field would result from the compression of the pre-shock ambient field by the expanding impact plasma (Hood, 1987). On the other hand, weaker anomalies are present within some Nectarian-aged impact basins (Halekas et al., 2003) that have recently been interpreted as plausibly due to TRM of slowly cooling impact-melt (Hood, in press; Wieczorek and Weiss, 2010). The latter anomalies may therefore be most consistent with the existence of a former dynamo, at least at the time of the Crisium impact and before.

Although the mechanism for transient antipodal magnetic field enhancement and shock magnetization has been modeled numerically (Hood and Huang, 1991; Hood and Artemieva, 2008), there is at the moment no experimental constraint on the shock magnetization of lunar rocks. This model now needs experimental validation: how strongly can the rocks from the lunar crust be magnetized by shock in presence of a magnetic field? Also, the part played by shock magnetization and demagnetization in the paleomagnetic signal of lunar samples is presently unknown.

Therefore it appears that for the interpretation of both the magnetic anomalies measured around the Moon and the paleomagnetic record of Apollo samples, it is mandatory to estimate quantitatively the shock remanent magnetization that lunar rocks can acquire for a given set of pressure and ambient magnetic field. In this paper, we present the first results of experimental acquisition of shock remanence by lunar rocks and discuss their implications for the interpretation of the paleomagnetic record of these rocks, as well as for the validity of the antipodal magnetization model.

\section{Shock magnetization of lunar materials: state-of-the-art}

There have been very few studies on the effects of shock on the magnetization of lunar materials. Preliminary data of shock- and piezoremanent magnetization on Mare basalts were published by Nagata et al. (1972), but the maximum pressure in this work was only $0.05 \mathrm{GPa}$. Preliminary shock experiments at higher pressures (in the 5 to $25 \mathrm{GPa}$ range) were undertaken by Fuller et al. (1974) on lunar soils. Magnetization by shock was indeed observed but cannot be safely described as SRM because the experiments involved other effects such as lithification, sintering, possible formation of iron from ferromagnesian minerals, changes in intrinsic magnetic properties, and significant heating. Moreover the magnetization during the shock at highest pressure (25 GPa) was not unidirectional when AF demagnetized. The magnetic mineralogy of lunar rocks is dominated by metallic $\mathrm{FeNi}$, mostly in the form of kamacite (e.g., Fuller and Cisowski, 1987; Fuller, 1998; Rochette et al., 2010). Preliminary results of shock magnetization of iron particles indicated that SRM at 1 GPa was about a fourth of TRM acquired in the same field (Pohl and Eckstaller, 1981). However, these experiments were performed on large particles (cylinders $\varnothing$ $200 \mu \mathrm{m} \times 200 \mu \mathrm{m}$ in length) that are by far out of the iron particles size range for lunar rocks. Shock magnetization of fine particle iron ( 20 to $100 \mathrm{~nm}$ in size) up to $5 \mathrm{GPa}$ has been addressed by Dickinson and Wasilewski (2000) who estimated that it could acquire a SRM on the order of 1 to $10 \%$ of the TRM. However this result is hardly applicable to lunar rocks because it is strongly dependent on grain size and the presence of nickel. Therefore it appears that there is presently no direct or indirect way to estimate the intensity of SRM acquired by lunar rocks at a given pressure in a given field, and to predict the coercivity spectrum of this SRM.

The fundamental properties of SRM acquired at low pressure $(<5 \mathrm{GPa})$ are well established. SRM is proportional to the ambient field in the low field $(<\sim 1 \mathrm{mT}$ ) limit (Pohl et al., 1975; Gattacceca et al., 2008) and is strictly parallel to the ambient magnetic field for magnetically isotropic rocks (Gattacceca et al., 2008). It is homogeneous in direction down to a scale of at least $\sim 0.2 \mathrm{~mm}^{3}$ (Gattacceca et al., submited). Its intensity is independent of the angle between the shock wave propagation direction and the ambient field for isotropic rocks, and can be significant compared to thermoremanent magnetization (TRM) acquired in the same ambient field (e.g. up to $36 \%$ in magnetitebearing rocks, Gattacceca et al., 2008). Its intensity is also independent from the pre-shock remanence (Gattacceca et al., 2010). Finally, the coercivity spectrum of SRM is shifted towards lower values compared to that of TRM (Gattacceca et al., 2008; 2010). These properties mean that SRM acquired at pressures lower than $5 \mathrm{GPa}$ can be considered as a reliable source of information about paleofields at the moment of impact, for direction but also for intensity provided proper calibration is achieved. For pressures higher than $~ 5 \mathrm{GPa}$ however, shock waves can permanently modify the intrinsic magnetic properties of rocks (Gattacceca et al., 2007; Gilder and Le Goff, 2008; Louzada et al., 2010) and the SRM direction may be linked to the shock direction (Funaki and Syono, 2008).

Metallic FeNi has a ferromagnetic body-centered cubic to antiferromagnetic hexagonal close packed phase transition at high pressure. The transition pressure decreases with increasing Ni content and is about $13 \mathrm{GPa}$ for pure $\mathrm{Fe}$, and about $9 \mathrm{GPa}$ for $\mathrm{Fe}_{20} \mathrm{Ni}_{80}$ (Wasilewski, 1976). The relevant pressure range to study SRM of FeNi-bearing rocks is therefore below $10 \mathrm{GPa}$ because at higher pressure SRM cannot increase any more (equivalent to heating a rock above its Curie temperature when studying TRM acquisition), and shock induced heating plays an increasing role. Moreover, during a hypervelocity impact on a planetary surface, the volume of rocks submitted to pressure in the $0.5-5 \mathrm{GPa}$ range is about 40 times larger than the volume of rocks submitted to pressure in excess of $5 \mathrm{GPa}$ (estimated from Louzada and Stewart, 2009). Finally, as proposed for Mars (Arkani-Hamed, 2005), the upper few $\mathrm{km}$ of the ancient lunar crust have probably been shocked to at least $2 \mathrm{GPa}$. As a consequence, the most relevant pressure range to study the magnetic effects of shock on planetary surfaces is probably between 0 and $5 \mathrm{GPa}$. This is also the range where the shock cannot be detected using standard petrological criteria (e.g., Stöffler et al., 1991). As a consequence, a rock shocked to less than $5 \mathrm{GPa}$ is referred to as 
unshocked, whereas we will see in the following that lunar rocks can acquire SRM at much lower pressures.

\section{Experimental methods}

We used two different techniques to investigate the acquisition of magnetization upon pressure loading and release in an ambient field: shock waves created by a focused and pulsed laser, and hydrostatic pressure created in a non-magnetic pressure cell. These two types of experiments are designed to create respectively SRM and piezoremanent magnetization (PRM). In both cases, the remanence is acquired upon stress release. We present results from experiments performed directly on lunar rocks. Both Apollo samples and lunar meteorites were used. Both share the same magnetic mineralogy (Rochette et al., 2010), but the latter gives access to lithologies that are poorly represented or absent in the Apollo collection (anorthosite breccia for instance). However, terrestrial weathering may be a problem for some meteorites, with the possible occurrence of magnetic weathering products such as iron oxides.

\subsection{SRM acquisition through laser shocks}

For laser shock experiments, the samples in the form of $\sim 1 \mathrm{~cm}^{3}$ cubes were submitted to a Nd-glass laser pulse at LCD (Laboratoire de Combustion et de Détonique, Poitiers, France). The laser spot diameter at the sample surface was $4.7 \mathrm{~mm}$. The laser shots were performed in water-confined regime. The ambient magnetic field was controlled by three orthogonal pairs of Helmholtz coils. This experimental setting is described in detail in Gattacceca et al. (2006; 2008). For each laser shot, the pulse duration ( $30 \mathrm{~ns}$ in this study), shape, and energy (16 J maximum in this study) were recorded. The energy at the surface of the sample was adjusted by intercalating neutral densities along the laser path. Power densities used in this work are in the range $0.5-4 \mathrm{GW} \mathrm{cm}^{-2}$. Shock wave propagation was modeled in a 2D axisymmetric configuration using the Radioss software and the Hyperworks suite from Altairß. As discussed in Gattacceca et al. (2008), it is noteworthy that the volume of rock heated by the laser beam and subsequent high-pressure plasma is restricted to a thin layer of only 10-20 $\mu \mathrm{m}$ located directly below the laser spot, which makes up a maximum of $310^{-10} \mathrm{~m}^{3}$ of rock heated above its Curie temperature. Any thermoremanence acquired during the laser experiments by this small volume of rock would be orders of magnitude lower than the SRM discussed in $\S 5$. The shock wave itself induces a temperature increase that is negligible (typically about a few ${ }^{\circ} \mathrm{C}$ ) for the pressures encountered in this work (e.g. Stöffler et al., 1991).

Four Mare basalt samples collected during the Apollo missions were used for these shock experiments: 14053 (specific sub-sample 14053,29), 15555 (15555,977), 15556 (15556,21), and 70215
$(70215,36)$. Before the shock experiments, the natural remanent magnetization (NRM) of these samples was measured and stepwise demagnetized using alternating field (AF) demagnetization up to $150 \mathrm{mT}$, using a with a 2G Superconducting Rock Magnetometer at CEREGE (Aix-en-Provence, France) for samples 14053 and 70215, and at HIGP-SOEST (University of Hawaii, Honolulu) for 15555 and 15556. Both magnetometers have a noise level of $10^{-11} \mathrm{Am}^{2}$. The oriented sample was then submitted to a laser shock in a known ambient field. After the shock, the remanent magnetization of the sample was measured. Supposing that the residual pre-shock magnetization is not affected by the shock (in view of its high coercivity), the vectorial difference between the post-shock magnetization and the pre-shock magnetization provides the SRM moment (see Fig. 2e-f for examples). The SRM was subsequently stepwise demagnetized with AF. Because the laser shock technique is non-destructive, each sample was submitted to repeated SRM acquisition experiment, up to 24 for sample 70215. During the whole process (shock and subsequent demagnetization of the SRM), the sample was set in a plastic holder designed to perform the laser shock in a water-confined regime, and to fit in a Agico JR5 spinner magnetometer (noise level $510^{-11} \mathrm{Am}^{2}$ ) and a Molspin tumbler AF demagnetizer that were brought on site in Poitiers. Only the SRM resulting from the last shock experiment was measured at CEREGE using the $2 \mathrm{G}$ magnetometer.

\subsection{PRM acquisition through hydrostatic loading experiments in pressure cell}

For pressure cell experiments, we used a non-magnetic pressure cell of a piston-cylinder type similar to the one described in Sadykov et al. (2008) with the difference that the entire cell is made of Russian alloy $\left(\mathrm{Ni}_{57} \mathrm{Cr}_{40} \mathrm{Al}_{3}\right)$ which allows pressure loading up to $1.8 \mathrm{GPa}$. Pressure loading is perfectly hydrostatic due to the use of a liquid pressure-transmitting medium (polyethilsiloxane). The inner diameter of the cell is $8 \mathrm{~mm}$. The maximum dimensions of the sample in the cell are $\varnothing 7 \mathrm{~mm} \times 20 \mathrm{~mm}$. The magnetic moment of the whole cell is about $210^{-8} \mathrm{Am}^{2}$ for a mass of $450 \mathrm{~g}$. Pressure loading in the cell was achieved with a press located in a magnetically shielded room (field $<400 \mathrm{nT}$ ). A solenoid coil connected to a stabilized DC supply and mounted on an aluminum support was designed to fit around the body of the pressure cell and calibrated with a Bartington MAG-01 fluxgate magnetometer. With this coil, a known field could be generated inside the pressure cell along the long axis of the cell. Pressure calibration of the cell was performed by fitting the pressure demagnetization curve of a synthetic magnetite-bearing sample that had already been pressure demagnetized with another pressure cell (Bezaeva et al., 2010) whose pressure was calibrated using a manganin sensor (Sadykov et al., 2008). The results of this calibration show that the actual pressure on the sample is about $10 \%$ lower than

Table 1

Rock magnetic properties of studied samples.

\begin{tabular}{|c|c|c|c|c|c|c|c|c|c|c|}
\hline & $\begin{array}{l}\text { Mass } \\
(\mathrm{g})\end{array}$ & $\begin{array}{l}\text { Mrs } \\
\left(\mathrm{A} \mathrm{m}^{2} \mathrm{~kg}^{-1}\right)\end{array}$ & $\begin{array}{l}\text { MDF of sIRM } \\
(\mathrm{mT})\end{array}$ & $\begin{array}{l}\text { Ms } \\
\left(\mathrm{A} \mathrm{m}^{2} \mathrm{~kg}^{-1}\right)\end{array}$ & $\begin{array}{l}\mathrm{Bcr} \\
(\mathrm{mT})\end{array}$ & $\begin{array}{l}\mathrm{Bc} \\
(\mathrm{mT})\end{array}$ & $\begin{array}{l}\text { ARM } \\
\left(\mathrm{A} \mathrm{m}^{2} \mathrm{~kg}^{-1}\right)\end{array}$ & $\begin{array}{l}\text { MDF ARM } \\
(\mathrm{mT})\end{array}$ & $\begin{array}{l}\chi \\
\left(\mathrm{m}^{3} \mathrm{~kg}^{-1}\right)\end{array}$ & $\begin{array}{l}\chi_{\mathrm{p}} \\
\left(\mathrm{m}^{3} \mathrm{~kg}^{-1}\right)\end{array}$ \\
\hline \multicolumn{11}{|c|}{ SRM experiments } \\
\hline 14053 & 1.39 & & & & & & $1.87 \mathrm{E}-03$ & 6 & $1.12 \mathrm{E}-05$ & \\
\hline 15555 & 3.24 & $3.82 \mathrm{E}-04$ & 17 & $1.02 \mathrm{E}-01$ & 30.8 & 1.34 & $7.71 \mathrm{E}-06$ & 7 & $8.44 \mathrm{E}-07$ & $4.85 \mathrm{E}-07$ \\
\hline 15556 & 2.49 & $4.53 \mathrm{E}-04$ & 20 & $9.98 \mathrm{E}-02$ & 37.1 & 1.46 & $2.75 \mathrm{E}-05$ & 10 & $7.62 \mathrm{E}-07$ & $4.60 \mathrm{E}-07$ \\
\hline 70215 & 3.23 & & & & & & $4.21 \mathrm{E}-05$ & 10 & $1.14 \mathrm{E}-06$ & \\
\hline \multicolumn{11}{|c|}{ PRM experiments } \\
\hline 14053 & 0.082 & $9.10 \mathrm{E}-03$ & 4 & 1.19 & 9.9 & 1.4 & $1.94 \mathrm{E}-03$ & 4 & $1.36 \mathrm{E}-05$ & $5.23 \mathrm{E}-07$ \\
\hline 15556 & 0.109 & $5.11 \mathrm{E}-04$ & 22 & $9.62 \mathrm{E}-02$ & 40.6 & 1.03 & $2.64 \mathrm{E}-05$ & 12 & $8.01 \mathrm{E}-07$ & $4.24 \mathrm{E}-07$ \\
\hline 70215 & 0.054 & $1.04 \mathrm{E}-03$ & 27 & $1.84 \mathrm{E}-01$ & 46 & 2 & $6.51 \mathrm{E}-05$ & 9 & $9.35 \mathrm{E}-07$ & $4.22 \mathrm{E}-07$ \\
\hline NEA 001 & 0.158 & $5.06 \mathrm{E}-03$ & 55 & $8.33 \mathrm{E}-02$ & 64 & 10.7 & $3.68 \mathrm{E}-04$ & 37 & $7.55 \mathrm{E}-07$ & $8.51 \mathrm{E}-08$ \\
\hline NWA 5406 & 0.144 & $7.85 \mathrm{E}-03$ & 28 & $8.29 \mathrm{E}-01$ & 44 & 2.6 & $2.70 \mathrm{E}-04$ & 18 & $4.37 \mathrm{E}-06$ & $1.74 \mathrm{E}-07$ \\
\hline
\end{tabular}

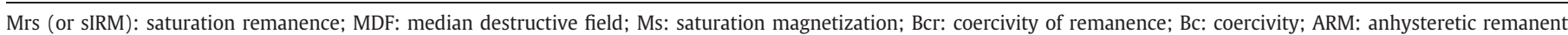
magnetization (acquired in a $170 \mathrm{mT} \mathrm{AF}$ and a $300 \mu$ T bias field; $\chi$ is low field magnetic susceptibility; $\chi_{\mathrm{p}}$ is high-field magnetic susceptibility. 
the pressure computed from the known external load, due to the effect of piston friction in the cell (Fig. A SOM).

For the pressure cell experiments, we used chips in the $50-150 \mathrm{mg}$ range from three Mare basalts used for the shock experiments (samples 14053,15556 , and 70215), as well as two highland rocks in the form of anorthositic regolith breccia lunar meteorites (NEA 001 and NWA 5406). The experimental protocol was the same for each sample. After $\mathrm{AF}$ demagnetization at $150 \mathrm{mT}$, the sample is set in a teflon capsule in the cell (see details in Sadykov et al., 2008 and Bezaeva et al., 2010). After application of a known magnetic field ( $800 \mu \mathrm{T}$ in this study) along the long axis of the cell, a given load is applied on the cell. After a $1 \mathrm{~min}$ pause at maximum pressure, the load is released slowly in the presence of the applied magnetic field. The sample is then extracted from the cell and its magnetic remanence measured and AF demagnetized using the $2 \mathrm{G}$ magnetometer at CEREGE. As in laser shock experiments, these pressure cell experiments are non-destructive, and the same samples have been submitted to successive PRM acquisition experiments with variable pressures and magnetic field intensities.

\subsection{Rock magnetism}

The main intrinsic magnetic properties of the studied samples were determined by standard magnetic analysis at CEREGE. This includes low field magnetic susceptibility using a Agico MFK1 apparatus, hysteresis parameters and high-field susceptibility (using a Princeton Micromag vibrating sample magnetometer), and AF demagnetization of saturation remanence (imparted with a MMTD pulse magnetizer at $3 \mathrm{~T}$, and measured with a $2 \mathrm{G}$ magnetometer).

\section{Magnetic properties of studied samples}

\subsection{Intrinsic magnetic properties}

A list of studied samples with their magnetic properties is given in Table 1. Hysteresis cycles of all samples (published in Rochette et al., 2010 for Apollo samples and displayed in Fig. B SOM for lunar meteorites) show the dominance of multidomain metallic FeNi (indicated by the curvature up to $0.8 \mathrm{~T}$ due to the high demagnetizing field) typical of lunar materials (Fuller and Cisowski, 1987). Impactprocessed samples (NEA 001 and NWA 5406) are more magnetic than mare basalts, because of meteoritic contamination (Rochette et al., 2010). The hysteresis loop of NEA 001 displays a significant aperture that may be attributed to terrestrial weathering products in the form of iron oxides or oxihydroxides. Although they share a rather similar magnetic mineralogy (with the exception of 14053), the samples show a variety of coercivity spectra with MDF in the range 4 to $55 \mathrm{mT}$ (Fig. 1a). The original magnetic properties of these rocks may have been modified by strong shocks (> 5 GPa) at the surface of the Moon (Gattacceca et al., 2007; Gilder and Le Goff, 2008; Louzada et al., 2010). However, since shock magnetization is acquired upon stress release, the relevant magnetic properties are the post-shock ones (as measured today) and not the original ones.

The magnetic mineralogy of 14053 has already been studied in detail (Nagata et al., 1972; Collinson et al., 1972). Thermomagnetic analyses of 14053 evidence the dominance of metallic Fe with a Curie temperature of $765^{\circ} \mathrm{C}$ (Nagata et al., 1972; Collinson et al., 1972). However, the unblocking temperatures of the NRM of 14053 are mostly below $300^{\circ} \mathrm{C}$ (Dunn and Fuller, 1972; Collinson et al., 1972) and this cannot be accounted for by a partial TRM mechanism as shown by the considerable differences between NRM and partial TRM thermal demagnetization (Collinson et al., 1972). This led Rochette et al. (2010) to suggest that cohenite $\left[(\mathrm{Fe}, \mathrm{Ni})_{3} \mathrm{C}\right]$ or screibersite $\left[(\mathrm{Fe}, \mathrm{Ni})_{3} \mathrm{P}\right]$ may be present in this sample. We performed thermal demagnetization of the saturation remanence of a sample of 14053 (Fig. 1c). The unblocking temperatures spectrum peaks at about $215-230^{\circ}$, with only $20 \%$ of the initial sIRM left at $280{ }^{\circ} \mathrm{C}$. This indicates that the remanence may be indeed dominated
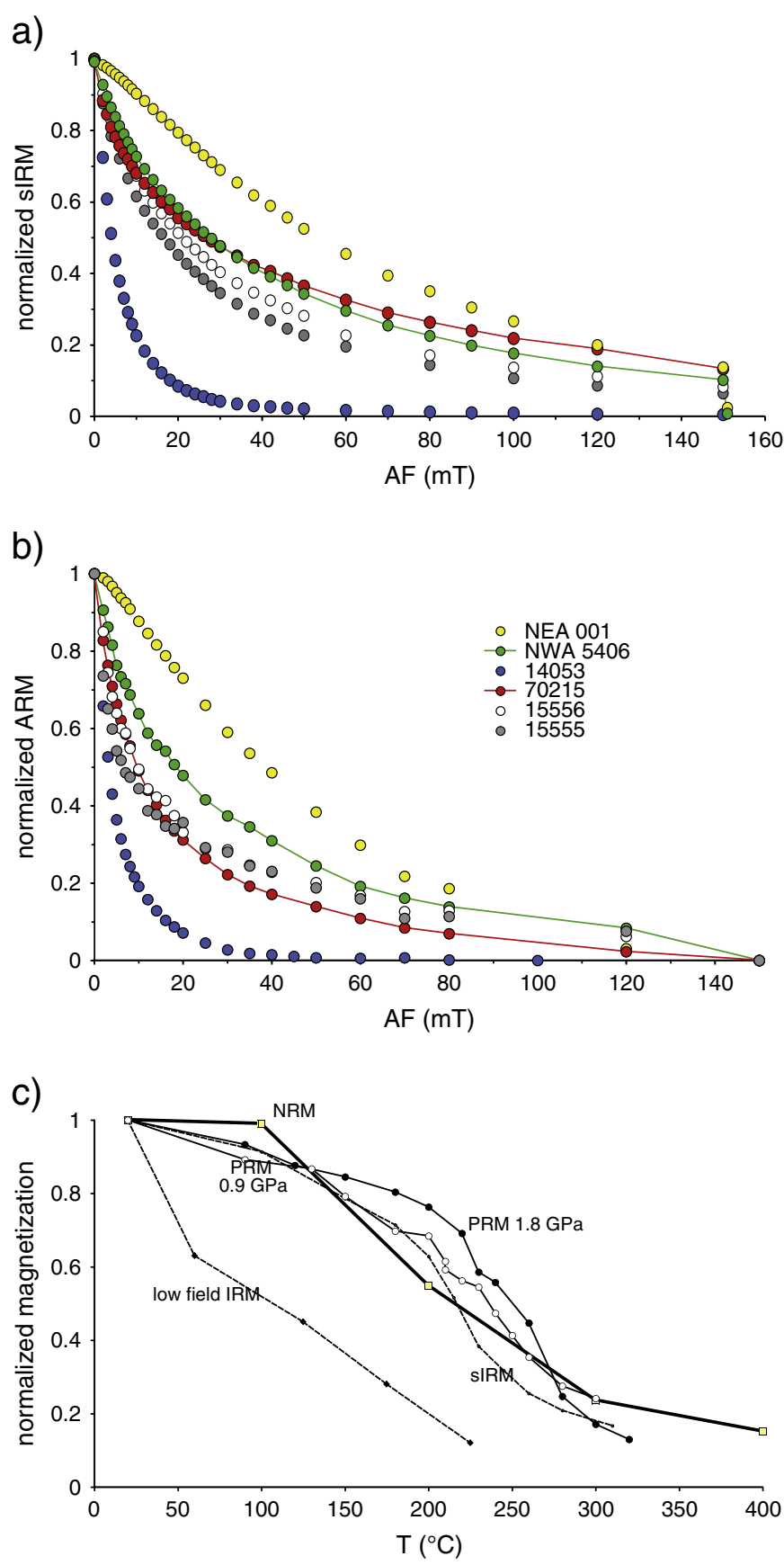

Fig. 1. a) Normalized sIRM versus AF for all studied samples. The datapoint at $151 \mathrm{mT}$ AF correponds to high-field demagnetization at $1 \mathrm{~T}$ with a VSM. b) Normalized anhysteretic remanent magnetization (acquired in an $\mathrm{AF}$ of $170 \mathrm{mT}$ and a bias field of $300 \mu \mathrm{T}$ ) versus $\mathrm{AF}$ for all studied samples. c) Thermal demagnetization of sample 14053: sIRM (this study), PRM at 0.9 and $1.8 \mathrm{GPa}$ (this study), low field (0.5-2 mT) IRM (Collinson et al., 1972), NRM (Dunn and Fuller, 1972).

by cohenite, pure stochiometric cohenite having a Curie temperature of $215^{\circ} \mathrm{C}$. No cohenite signal is visible on the saturation magnetization (Ms) versus temperature experiment of Collinson et al. (1972). In view of the relative $M s$ values for kamacite $\left(220 \mathrm{Am}^{2} \mathrm{~kg}^{-1}\right)$ and cohenite $\left(140 \mathrm{Am}^{2} \mathrm{~kg}^{-1}\right)$, this absence implies a maximum cohenite/kamacite ratio of about 3\%. But in view of the very low ratio of saturation remanence to saturation magnetization (Mrs/Ms) of kamacite in lunar Mare basalts (generally $<0.005$, see e.g. Rochette et al., 2010), $3 \%$ of a magnetically harder cohenite with Mrs/Ms of a few 0.1 would be enough to account for the observed thermal demagnetization of the remanence. 
a)

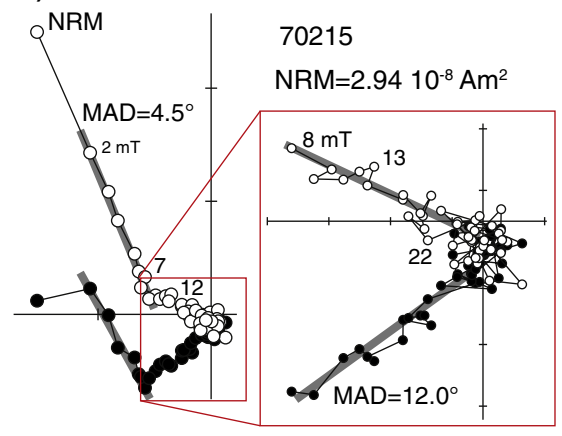

c)

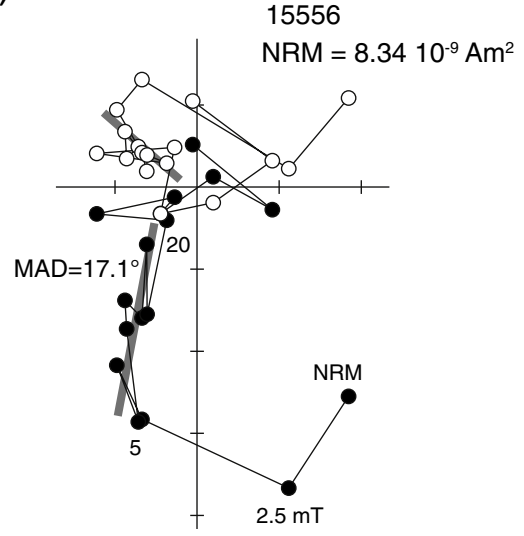

b)

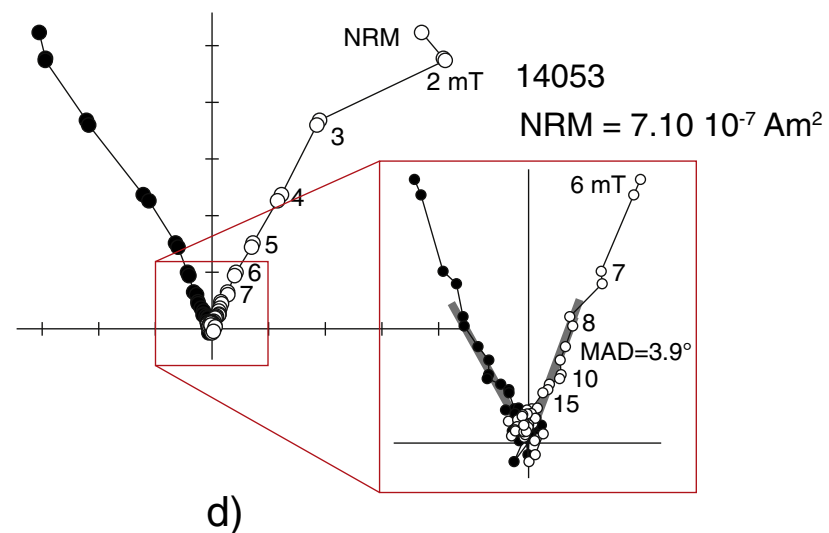

d)

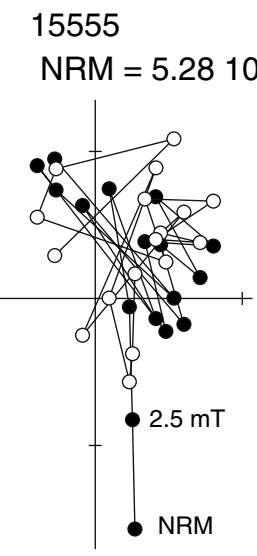

e)

70215

$\mathrm{SRM}=1.5210^{-8} \mathrm{Am}^{2}$

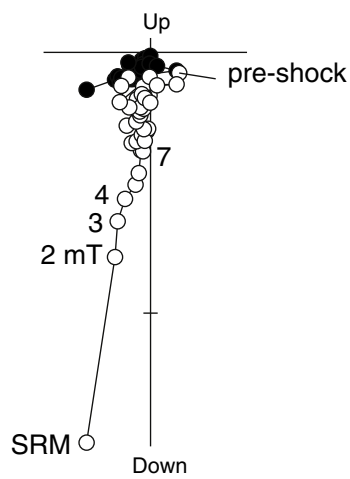

f)

14053

$\mathrm{SRM}=4.7910^{-7} \mathrm{Am}^{2}$

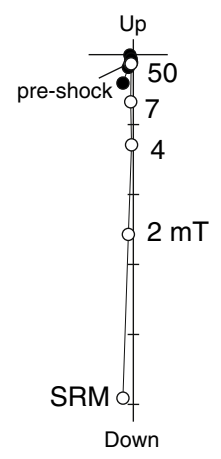

g) 15556

$\mathrm{PRM}=3.6310^{-9} \mathrm{Am}^{2}$

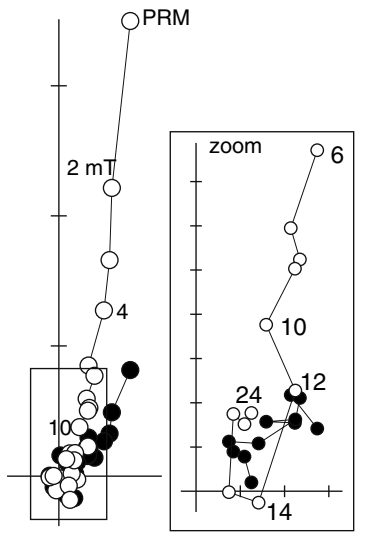

h)
NWA 5406

$\mathrm{PRM}=2.9410^{-8} \mathrm{Am}^{2}$

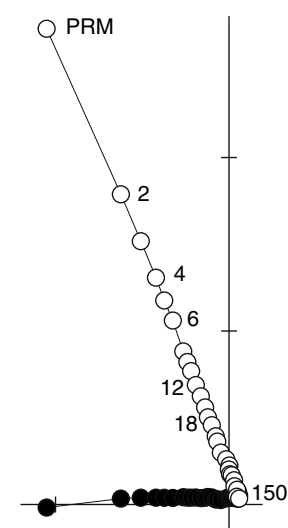

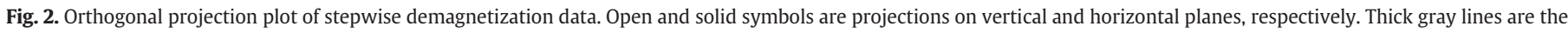

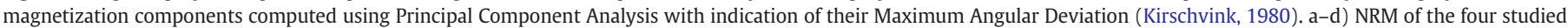

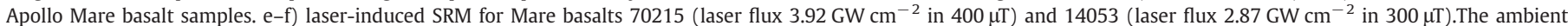
magnetic field during impact was vertical downward. g-h) PRM imparted in the pressure cell for samples 15556 (1.8 GPa in $1762 \mu \mathrm{T})$ and NWA 5406 (1.8 GPa in $881 \mu \mathrm{T})$.

Before the shock experiments, anhysteretic remanent magnetization (ARM) acquired in an alternating field of $170 \mathrm{mT}$ and a bias field of $300 \mu \mathrm{T}$ was measured and demagnetized with $\mathrm{AF}$ as an analogue to TRM (Fig. 1b). ARM was also measured and demagnetized with AF after the shock experiments: the measurements are indistinguishable from the pre-shock measurements which indicates that the low pressure used in this work $(<2 \mathrm{GPa})$ did not change the coercivity spectrum of the samples, as expected for peak pressure below 3-5 GPa (Gattacceca et al., 2007; Louzada et al., 2010).

\subsection{Natural remanent magnetization}

NRM demagnetization data are displayed in Fig. 2a-d, together with the mean direction computed using principal component analysis (Kirschvink, 1980). These NRMs were measured on the same samples that were used for our pressure experiments. Sample 14053 has an almost unidirectional magnetization trending toward the origin, and a very stable direction (maximum angular deviation, $\mathrm{MAD}=3.9^{\circ}$ ) can be isolated between 5 and about $25 \mathrm{mT}$. Sample 
$1 \mathrm{GW} . \mathrm{cm}^{-2}$
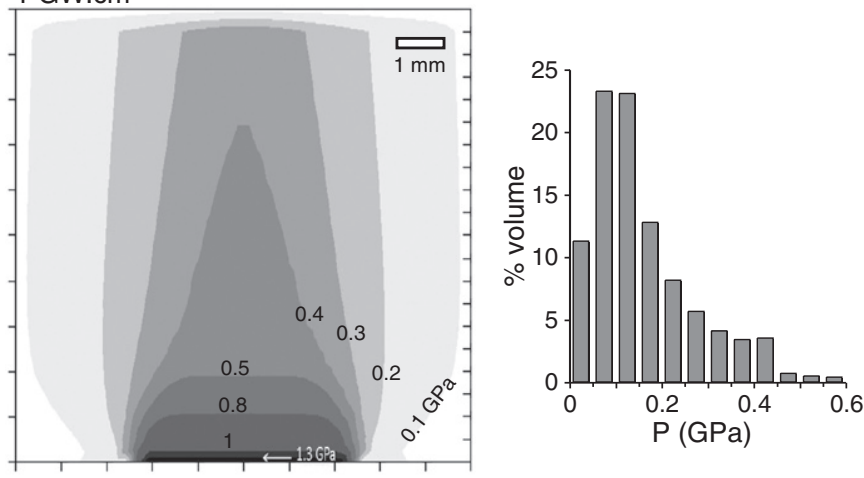

$2 \mathrm{GW} . \mathrm{cm}^{-2}$

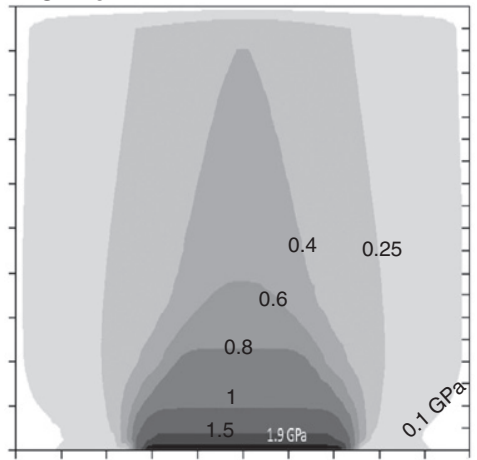

$3 \mathrm{GW} . \mathrm{cm}^{-2}$
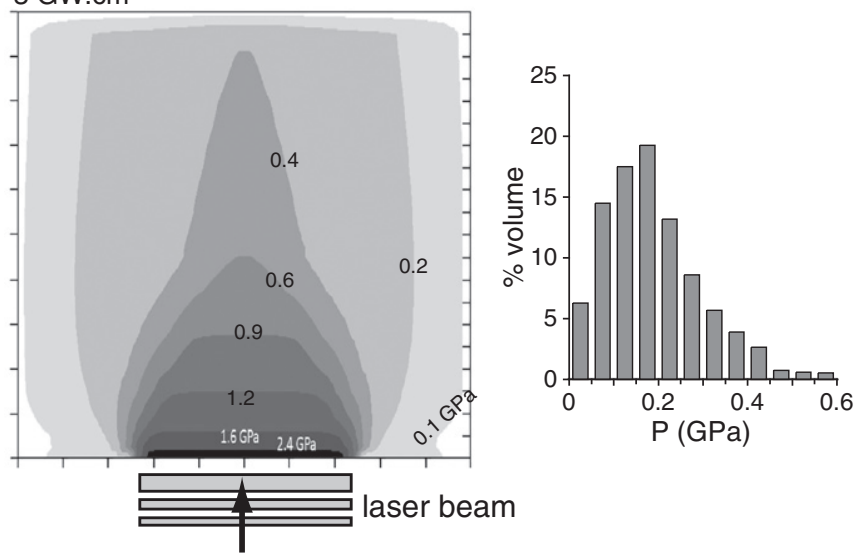

Fig. 3. Modeled peak pressure isocontours in the Mare basalts sample upon laser shock with a flux of 1,2 , and $3 \mathrm{GW} \mathrm{cm}{ }^{-2}$ focused on a spot of $4.7 \mathrm{~mm}$ in diameter in waterconfined regime. The flat front face of each cubic sample (10 mm edge) is at the bottom, and the laser pulse is coming from the bottom up. Associated peak pressure histograms are also plotted.

70215 displays two components of magnetization isolated between 2 and $7 \mathrm{mT}\left(\mathrm{MAD}=4.5^{\circ}\right)$, and 7 and $25 \mathrm{mT}\left(\mathrm{MAD}=12^{\circ}\right)$ respectively. Mare basalt sample 15555 has a weak and soft remanent magnetization from which no stable component can be isolated. Sample 15556 displays a low coercivity component below $5 \mathrm{mT}$ and a poorly defined component of magnetization ( $\mathrm{MAD}=18.3^{\circ}$ ) between 5 and $20 \mathrm{mT}$. For these three samples, the "high" coercivity components deviate from the origin by less than their uncertainty represented by the MAD, which is consistent with these components trending to the origin. The NRM data for the two meteorites is not discussed here because the possible weathering effects and the demonstrated exposure to a strong magnet by meteorite hunters make the interpretation too tentative. a)

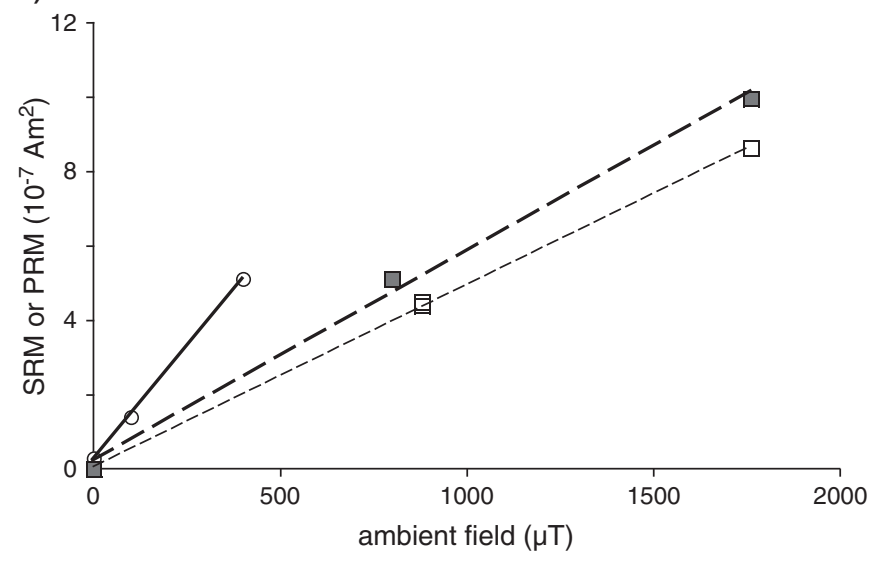

b)

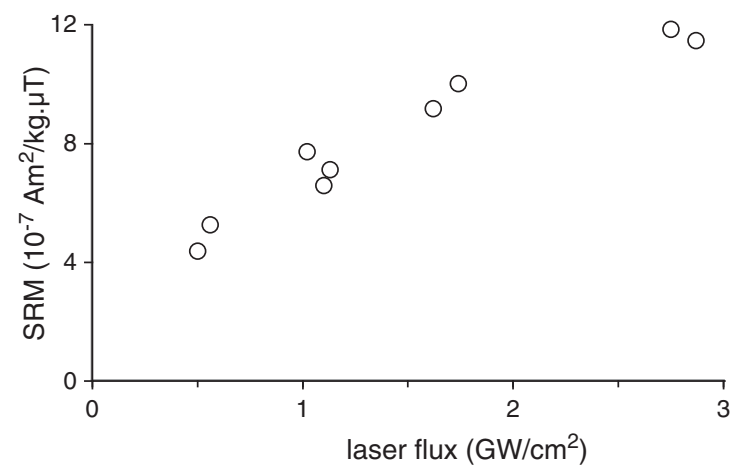

Fig. 4. a) SRM acquired with a constant laser flux of $1.6-1.7 \mathrm{GW} \mathrm{cm}^{-2}$ (dots, linear fit indicated by solid line), and PRM at $0.9 \mathrm{GPa}$ (empty boxes, thin broken line) and at $1.8 \mathrm{GPa}$ (solid boxes, thick broken line) of sample 14053 as function of ambient field; b) SRM (normalized by the magnetizing field) of sample 14053 as a function of laser flux.

The NRM of 14053 and 70215 had already been studied by AF demagnetization and thermal demagnetization (Dunn and Fuller, 1972; Collinson et al., 1972; Hargraves and Dorety, 1975; Stephenson et al., 1974). These results are discussed in detail in Fuller and Cisowski (1987). For 14053, previous results also evidence a stable component of NRM isolated above $6 \mathrm{mT} \mathrm{AF}$ or $100{ }^{\circ} \mathrm{C}$ (Collinson et al., 1972). The coercivity spectrum of this NRM is different from that of TRM, pTRM, and sIRM (Dunn and Fuller, 1972). For 70215, previous result also demonstrated directional stability of the NRM upon AF demagnetization up to $11.5 \mathrm{mT}$, but thermal demagnetization evidenced two antipodal components of magnetization (Stephenson et al., 1974). Therefore the previous studies of the NRM of 70215 are somewhat difficult to interpret. Considering that the NRM of 70215 is a TRM, tentative paleointensity determinations of $\sim 5 \mu \mathrm{T}$ were proposed by Stephenson et al. (1974). The NRM of 15556 has been studied in an ongoing work by Tikoo et al. (2010). AF demagnetization reveals two stable components of magnetization isolated between 0 and $7 \mathrm{mT}$, and between 7 and $20 \mathrm{mT}$, exactly like in the present study.

\section{Shock experiments}

The laser shock experiments were conducted with laser fluxes in the $0.5-4 \mathrm{GW} \mathrm{cm}^{-2}$ range and in ambient fields in the 200$400 \mu \mathrm{T}$ range. The modeled peak pressure isocontours (Fig. 3) illustrate the main caveat of this technique, namely the pressure heterogeneity in the shocked sample. The first important result is that lunar Mare basalts can indeed be magnetized by shock in the presence of an ambient field, even for low pressure ( $<1 \mathrm{GPa}$ ) shocks as evidenced by the results provided in Table 2. The SRM 
PRM and SRM results.

\begin{tabular}{|c|c|c|c|c|c|c|c|c|}
\hline & $\begin{array}{l}\text { Main sample } \\
\text { mass } \\
(\mathrm{g})\end{array}$ & $\begin{array}{l}\text { SRM } \\
\text { at } 0.2 \mathrm{GPa} \\
\left(\mathrm{Am}^{2} / \mathrm{kg} . \mu \mathrm{T}\right)\end{array}$ & $\begin{array}{l}\text { Sub-sample } \\
\text { mass } \\
(\mathrm{mg})\end{array}$ & 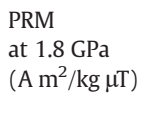 & $\begin{array}{l}\text { PRM at } 1.8 \mathrm{GPa} \\
\text { normalized to } \\
\text { sIRM } \\
\left(\mu \mathrm{T}^{-1}\right)\end{array}$ & $\begin{array}{l}\text { Estimated } \\
\text { maximum PRM } \\
\left(\mathrm{A} \mathrm{m} \mathrm{m}^{2} / \mathrm{kg} \mu \mathrm{T}\right)\end{array}$ & $\begin{array}{l}\text { Paleofield for } \\
\text { a } 1 \mathrm{~A} \mathrm{~m}^{-1} \mathrm{SRM} \\
\text { at } 1.8 \mathrm{GPa} \\
(\mu \mathrm{T})\end{array}$ & $\begin{array}{l}\text { Minimum estimated } \\
\text { paleofield for a } \\
1 \mathrm{~A} \mathrm{~m}-1 \mathrm{SRM} \\
(\mu \mathrm{T})\end{array}$ \\
\hline 14053 & 1.39 & $1.19 \mathrm{E}-06$ & 82 & $6.10 \mathrm{E}-06$ & $6.70 \mathrm{E}-04$ & $6.10 \mathrm{E}-06$ & 54 & 54 \\
\hline 15555 & 3.24 & $1.18 \mathrm{E}-08$ & & & & & & \\
\hline 15556 & 2.49 & $1.17 \mathrm{E}-08$ & 109 & $1.83 \mathrm{E}-08$ & $4.04 \mathrm{E}-05$ & $4.46 \mathrm{E}-08$ & 18094 & 7421 \\
\hline 70215 & 3.23 & $3.37 \mathrm{E}-08$ & 54 & $8.70 \mathrm{E}-08$ & $8.37 \mathrm{E}-05$ & $2.01 \mathrm{E}-07$ & 3483 & 1510 \\
\hline NEA 001 & & & 158 & $7.59 \mathrm{E}-08$ & $1.50 \mathrm{E}-05$ & $4.91 \mathrm{E}-07$ & 4363 & 674 \\
\hline NWA 5406 & & & 144 & $3.09 \mathrm{E}-07$ & $3.94 \mathrm{E}-05$ & $6.92 \mathrm{E}-07$ & 1072 & 478 \\
\hline
\end{tabular}

SRM results were obtained on the main samples. PRM results were obtained on sub-samples taken from the main samples.

moments are about two orders of magnitude larger than the preshock residual moments. The experiments are reproducible: for repeated shocks using the same laser power, the SRM variations are on average $5 \%$ of the mean SRM value. As expected, SRM increased linearly with ambient field (Fig. 4a), so that in the following SRM values are given after normalizing by the ambient field at the time of shock. SRM also increase with laser flux, i.e. with pressure (Fig. 4b). The SRM is characterized by low coercivities with median destructive fields (MDF) in the 2-5 mT range (Table 1). However, SRM is stable up to 20-30 mT in samples 14053 and 70215 (Fig. 2f-g). From these experiments, an estimate of SRM can be proposed for the four studied samples as a function of ambient field. However, determination of the pressure dependence of SRM would require cutting sub-samples at different distances from the impact spot, which could not be achieved for curatorial reasons. We therefore use the median maximum pressure in the sample ( $0.2 \mathrm{GPa}$ for all experiments, see Fig. 3$)$ as a rough indicator. At this pressure level, the SRM intensities (normalized to magnetizing field) range from $1.181^{-8}$ (for 15555) to $1.1910^{-6} \mathrm{Am}^{2} / \mathrm{kg} \mu \mathrm{T}$ (for 14053) and are listed in Table 2.
Although the pressure heterogeneity in the samples does not allow precise quantification of SRM as a function of pressure and precise determination of the SRM coercivity spectrum, these experiments, that could be performed on large samples were a good test to check if a SRM could be imparted to lunar rocks at relatively low pressure. The positive results prompted us to perform experiments in which pressure could be adequately monitored, namely piezo-remanent acquisition experiments.

\section{Hydrostatic pressure experiments}

\subsection{Piezo- versus shock remanent magnetization}

The typical time scale of the duration of the shock wave generated during a natural hypervelocity impact is on the order of a few ms to a few s depending on the impactor size and velocity. The laser shocks used in this study generated shock waves whose duration is $\sim 30 \mathrm{~ns}$. On the other hand, hydrostatic pressure was applied during $60 \mathrm{~s}$. Moreover, the deviatoric stress may play a role during shock experiment (Nagata,
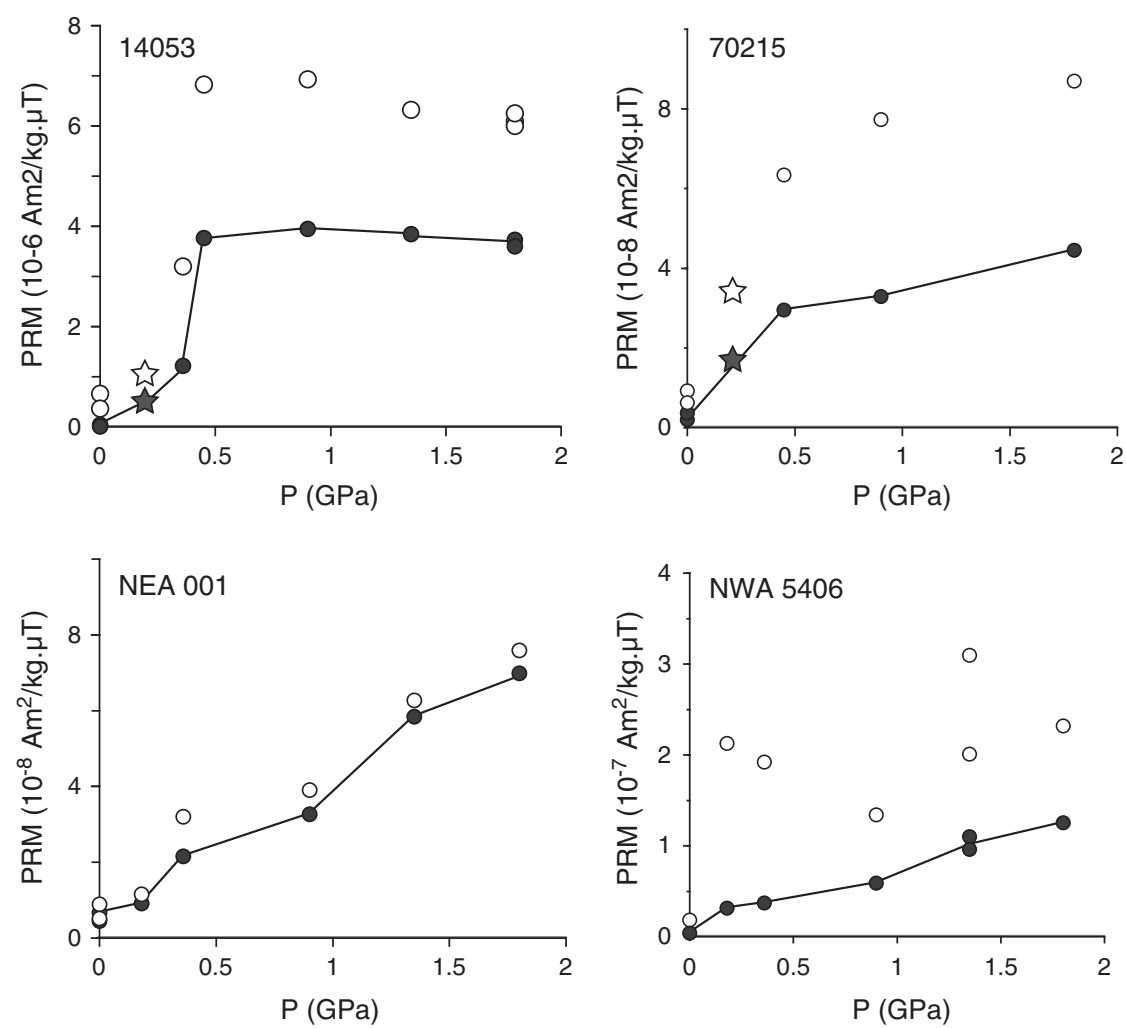

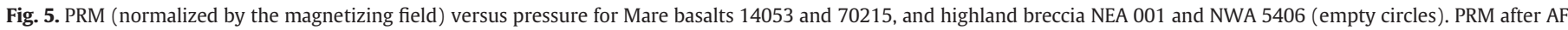

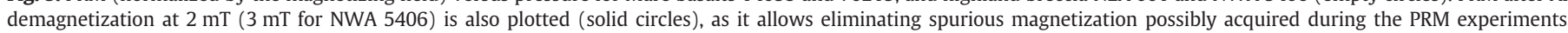

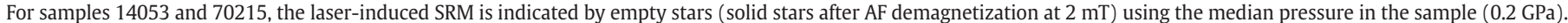



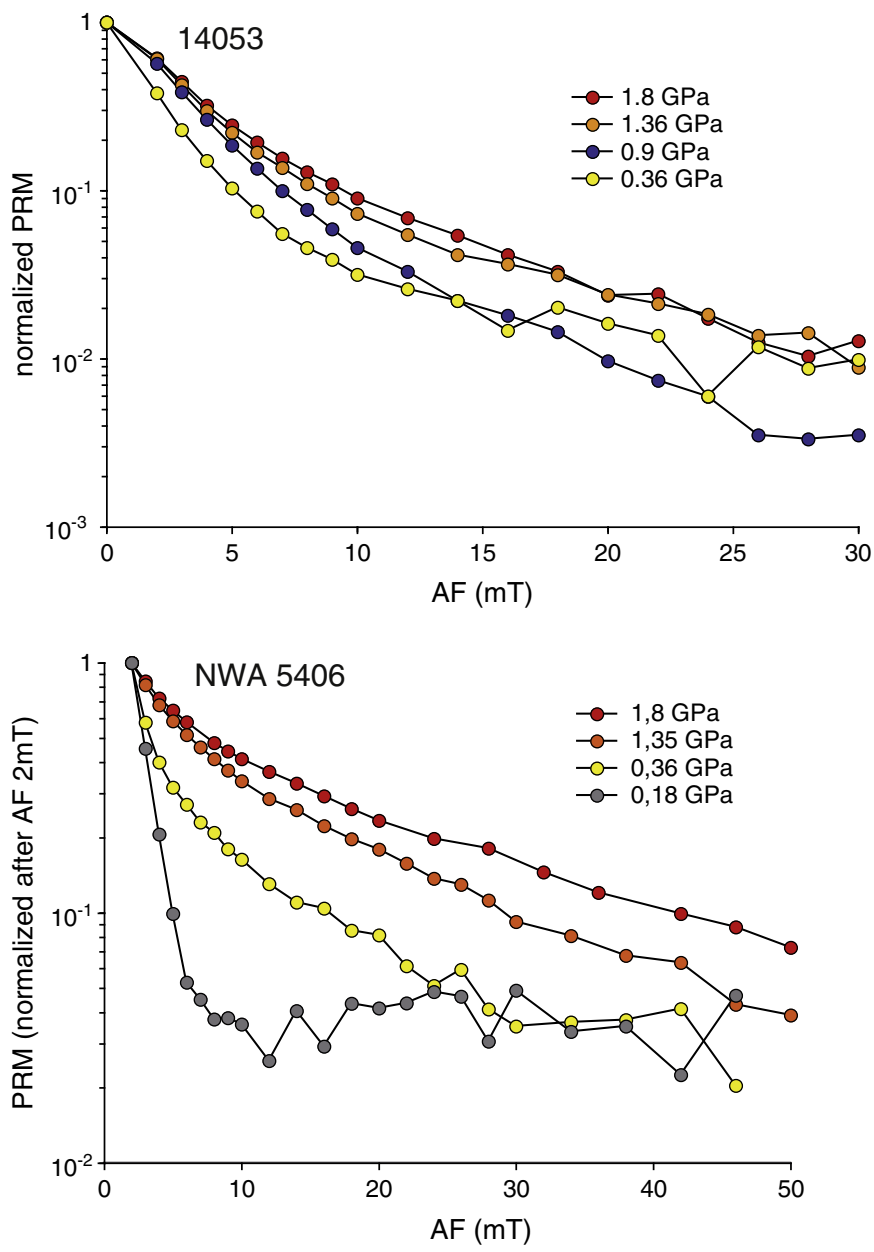

Fig. 6. Normalized PRM versus AF for different maximum pressure values, for samples 14053 and NWA 5406.

1966; Martin and Noel, 1988) that is not involved in hydrostatic experiments. It is therefore reasonable to wonder if PRM and laserinduced SRM are comparable in terms of intensity and properties. We present here a comparison of both types of magnetization for a terrestrial basalt and Allende meteorite. The basalt is a titanomagnetite-bearing basalt whose petrography and magnetic properties are

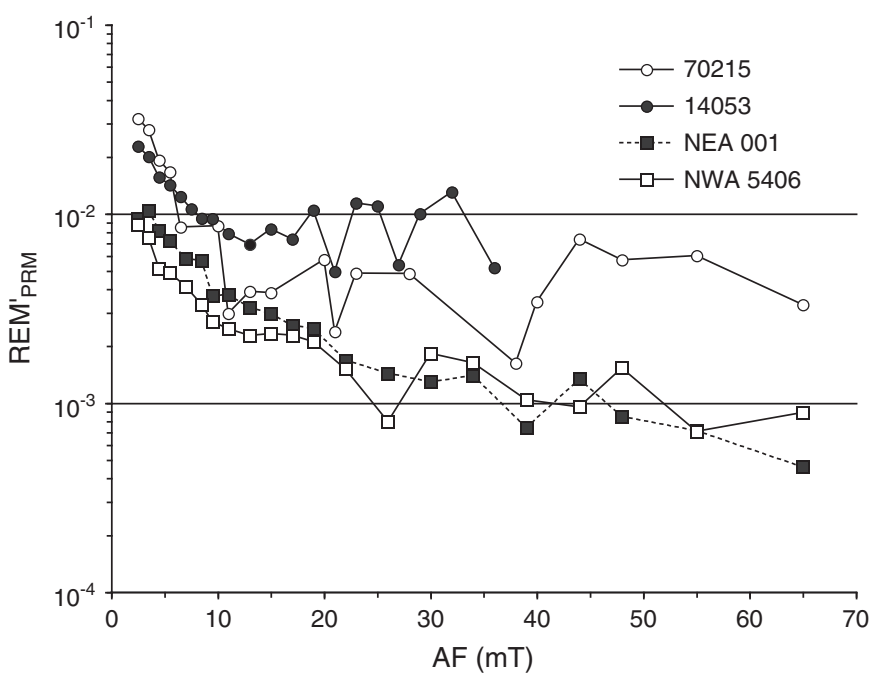

Fig. 7. REM' as a function of AF for the PRM of lunar samples acquired at $1.8 \mathrm{GPa}$ in $881 \mu \mathrm{T}$ ( $1762 \mu \mathrm{T}$ for sample 70215$)$ and normalized to an ambient field of $100 \mu \mathrm{T}$. described in Gattacceca et al. (2008). Allende meteorite contains a mixture of magnetite, pyrrhotite and FeNi metal (e.g., Butler, 1972). Determination of SRM intensity versus pressure for the laser experiments was conducted by cutting millimetric sub-samples at increasing distance from the laser impact. The results show that on the pressure range of interest ( 0.1 to a few GPa), PRM and laser-induced SRM are equivalent at first order (Fig. C SOM). We are therefore rather confident that there is no significant dependence of the duration of the application of the peak pressure on the acquired magnetization. In addition, the similarity of the demagnetizing effect of dynamic (laser-induced) and hydrostatic pressure experiments has already been demonstrated qualitatively (Gattacceca et al., 2010). It is very possible that pressure magnetization and demagnetization effects do not depend on the duration as far as it is longer than the characteristic time of spin reorientation, in the order of $10^{-10} \mathrm{~s}$ (Walton et al., 1991).

\subsection{PRM results}

We were able to impart a measurable PRM to each of the five studied samples (Table 2). PRM increases linearly with the magnetizing field (Fig. 4a), so that the PRM intensities given in the following are divided by the magnetizing field. The experiments are reproducible: for repeated loading at the same pressure, the PRM variations are on average $4 \%$ of the mean PRM value. PRM intensity increases with pressure up to at least $1.8 \mathrm{GPa}$ except for 14053 that reaches a plateau at about $0.4 \mathrm{GPa}$ (Fig. 5). In Figure 5, the data points at $0 \mathrm{GPa}$ correspond to experiments in which the samples were placed in the cell, the magnetizing field was applied for a few minutes (typical duration of a normal loading experiment), but no load was applied on the cell. The very weak magnetization acquired during these experiments at zero pressure proves that the magnetization acquired at higher pressure are not viscous remanent magnetizations or IRM acquired in the rather strong magnetizing fields of several hundreds of $\mu \mathrm{T}$.

The coercivity spectrum of PRM is shifted towards higher coercivity values with increasing pressure (Fig. 6). The REM' values (i.e. the ratio of the PRM lost over a given AF interval and the IRM lost over the same interval, as defined in Gattacceca and Rochette 2004) are displayed in Figure 7 and noted REM'PRM in the following. These values reflect the efficiency with which the different fractions of the coercivity spectrum have been magnetized by pressure. For 14053 , it is noteworthy that PRM plateaus at low pressure $(0.4 \mathrm{GPa})$ because this sample has a coercivity spectrum confined to low coercivity values (Fig. 1), so that there is no higher coercivity grains to be magnetized as pressure increase above $0.4 \mathrm{GPa}$. This behavior also translates in $\mathrm{REM}^{\prime}{ }_{\text {PRM }}$ values that are fairly constant over the whole AF range, as opposed to the other samples that show a marked decrease of $\mathrm{REM}^{\prime}{ }_{\mathrm{PRM}}$ values with increasing AF. From the REM' curves, a maximum PRM value can be derived, considering that the efficiency observed for low coercivity grains can be extrapolated to the whole coercivity spectrum at higher pressure, as is the case for 14053 that has already reached PRM saturation at $1.8 \mathrm{GPa}$. For 14053, NEA 001, NWA 5406, these maximum values (listed in Table 2) were computed using the REM' ${ }_{\text {PRM }}$ value at $3 \mathrm{mT}$ AF: the maximum PRM is the product of REM' ${ }^{\prime}$ PRM@3mT by sIRM, where the sIRM values are given in Table 1, and REM $^{\prime}{ }_{\text {PRM@3mT }}$ values can be read in Figure 7. For 70215 and 15556, whose PRM experiments were conducted in stronger ambient field ( $1762 \mu \mathrm{T}$ compared to $881 \mu \mathrm{T}$ ) they were computed using the REM' ${ }^{\prime}{ }_{\mathrm{PRM}}$ value at $4 \mathrm{mT}$ to avoid taking into account a possible contamination by viscous magnetization during PRM experiments.

\section{Discussion}

\subsection{SRM capacity of lunar rocks}

Based on shock and hydrostatic pressure experiments, we now have the experimental proof that lunar rocks can be magnetized by 
shock, and we can quantitatively estimate the shock magnetization as a function of pressure and ambient magnetic field. We will now discuss the implications of these results for the interpretation of lunar paleomagnetism (can SRM account for NRM and in that case what was the intensity of the ambient field at the time of impact?) and for the plausibility of the antipodal magnetic anomaly model of Hood (1987). As discussed in §6.1, SRM and PRM have equivalent properties and intensities at first order and in the following we will use the generic term SRM.

Except for 14053, that has a peculiar magnetic mineralogy with possible major contribution of cohenite, all samples show a rather similar maximum SRM capacity when normalized by SIRM, with an average of $1.210^{-4} \mu \mathrm{T}^{-1}$ (s.d. $0.410^{-4}$ ). This value can be regarded as a rough estimate of the maximum SRM that lunar rocks with standard magnetic mineralogy (i.e. dominated by multidomain FeNi with low Ni content) can acquire upon low pressure ( $<10 \mathrm{GPa})$ shocks. TRM of lunar rocks can be estimated using the empirical relation $\mathrm{B}=3 \times 10^{-3} \mathrm{TRM} / \mathrm{sIRM}$ (Gattacceca and Rochette, 2004) where $\mathrm{B}$ is the magnetizing field during TRM acquisition in T, which gives TRM/sIRM 3.3 $10^{-4} \mu \mathrm{T}^{-1}$. Therefore TRM appears approximately 3 times more efficient than the maximum SRM. ARM can also be used as a proxy for TRM using the empirical relationship TRM $=f^{\prime} \times$ ARM (with TRM and ARM normalized to their magnetizing field) with $f^{\prime}=1.34$ for equant multidomain iron (Stephenson and Collinson, 1974). The anisotropy of magnetic susceptibility measured on the same Apollo samples by Rochette et al. (2010) is weak, with anisotropy degrees of the ferromagnetic fraction below $8 \%$, which suggests that the FeNi minerals in these rocks are indeed rather equant. This approach gives an identical result with TRM about 2-3 times the maximum SRM, except for 14053 that gives TRM $\sim 1.4 \times$ SRM. This factor 3 difference between TRM and maximum SRM in lunar rocks can be compared with results obtained on large synthetic iron particles up to 1 GPa (Pohl and Eckstaller, 1981) and synthetic fine iron particles up to $5 \mathrm{GPa}$ (Dickinson and Wasilewski, 2000) which indicated that TRM was about 4 (respectively 10 to 100) times more efficient than SRM.

\subsection{Implications for lunar paleomagnetism}

As far as lunar paleomagnetism is concerned, we can compare the NRM and the SRM of the three studied Apollo samples that yielded an interpretable NRM record: 14053, 15556 and 70215. Normalized AF demagnetization curves of NRM and SRM show that for some samples (70215, 14053), NRM and SRM have indistinguishable coercivity spectra whereas sIRM and ARM are notably different from NRM (Fig. 8a), indicating that NRM could well have a shock origin. In the case of 14053 , it is noteworthy that NRM is more compatible with a SRM acquired at $0.9 \mathrm{GPa}$ than acquired at $1.8 \mathrm{GPa}$. Conversely, for sample 15556, even though the NRM data are noisy, the very different coercivity spectra of NRM and SRM discard a shock origin for the NRM. This, plus the similarity of the coercivity spectra of NRM and ARM (which is a good analogue for TRM), may imply that the NRM of 15556 is a TRM and therefore require a long standing stable magnetic field (namely a dynamo generated field) whose intensity can be estimated to about $55 \mu \mathrm{T}$ using the integrated REM' over the 5-20 mT AF interval where the stable NRM is isolated (Gattacceca and Rochette, 2004).

Because the NRM of 14053, 15556, and 70215 are not unidirectional, and because natural relaxation of the low coercivity fraction of the NRM is expected, the simple comparison of the AF demagnetization curves remains qualitative and it is necessary to compare the moments demagnetized over each AF demagnetizing step for NRM (noted $\triangle \mathrm{NRM}$ ) and SRM (noted $\triangle \mathrm{SRM}$ ) (Fig. 8b). AF demagnetization data for the PRM of 15556 are too noisy to use this approach. The stability of the ratio $\alpha=\Delta \mathrm{NRM} / \Delta \mathrm{SRM}$ ratio over the stability interval of NRM for 14053 and 70215 indicates that SRM can indeed account for the observed NRM. In that case, the paleointensity of the ambient field at the time of the putative shock can be computed as $\mathrm{B}=\alpha_{\text {stable }} \times \mathrm{B}_{\text {PRM }}$ where $\pm_{\text {stable }}$ is the integrated $\alpha$ over the interval of stable NRM (i.e. the ratio of the norm of the NRM vector demagnetized over the stability interval by the norm of the PRM vector demagnetized over the same interval), and $B_{P R M}$ is the field in which PRM was acquired. We obtain paleointensity of 40 to $60 \mu \mathrm{T}$ for 14053 (depending on which pressure is considered) and $240 \mu \mathrm{T}$ for 70215. For 70215 this value, computed for a $1.8 \mathrm{GPa}$ shock, must be regarded as a maximum value because shock at higher pressure would increase the PRM by a factor of several times (Figs. 5 and 6). Indeed, if we extrapolate the $\triangle \mathrm{NRM} / \triangle \mathrm{PRM}$ value at $4 \mathrm{mT}$ (Fig. $8 \mathrm{~b}$ ) to the 7-25 mT coercivity range, we end up with a minimum paleofield estimate of $95 \mu \mathrm{T}$. There is presently no reliable assessment for a realistic range for the intensity of a putative lunar dynamo field, but paleointensity values of $95 \mu \mathrm{T}$ would clearly lie in the very upper range of what is plausible (Wieczorek et al., 2006). On the other hand, any initial ambient magnetic field, including a dynamo field, can be transiently amplified by expansion of the partially ionized vapor-melt cloud produced in hypervelocity impacts (Hood and Artemieva, 2008).

Previous magnetic measurements on sample 14053 gave a NRM/sIRM ratio of $7.310^{-3}$ after $20 \mathrm{mT}$ AF demagnetization (Cisowski et al., 1983), and sample 70215 gave a NRM/sIRM ratio after (resp. before) $20 \mathrm{mT} \mathrm{AF}$ demagnetization of $1.610^{-2}$ (resp. $7.510^{-3}$ ) (Hargraves and Dorety, 1975). Such ratios may indicate relatively high paleointensities even for a thermoremanent process. In contrast, paleointensity estimates of $2-8 \mu \mathrm{T}$ were obtained on 70215 by Thellier-type methods (Stephenson et al., 1974). For 70215, in absence of a consensus for the TRM paleointensity, it is difficult to evaluate which explanation (SRM or TRM) is more plausible. Conversely, for 14053 a SRM origin in a field of $40 \mu \mathrm{T}$ may be a satisfying explanation because SRM is the only type of magnetization that has been shown to fit both the coercivity (Fig. 8a) and the unblocking temperature spectrum (Fig. 1c) of the NRM. Previous studies (Dunn and Fuller, 1972; Collinson et al., 1972) were also unable to simulate the AF demagnetization behavior of NRM with TRM, partial TRM, IRM or combination of these magnetizations. If the NRM of 14053 is indeed a SRM, the age of its magnetization would be anything younger than the last thermal event suffered by this rock during its complex thermal history (Taylor et al., 2004). Since only very low pressure ( $1 \mathrm{GPa})$ is required, this scenario is compatible with the absence of petrologic evidence for shock in 14053 (El Goresy and Ramdohr, 1975).

\subsection{Implications for the antipodal magnetic anomalies model}

As far as the antipodal magnetic anomaly model is concerned, such anomalies require magnetization of about $1 \mathrm{~A} \mathrm{~m}^{-1}\left(\sim 310^{-4} \mathrm{Am}^{2} \mathrm{~kg}^{-1}\right)$ over several kilometers of thickness (e.g., Hood and Artemieva, 2008). Such magnetization level can be obtained by 14053 with a shock as low as $0.4 \mathrm{GPa}$ in $\sim 50 \mu \mathrm{T}$. But all the other samples require magnetizing field of several hundreds of $\mu \mathrm{T}$ to be shock magnetized to such levels. According to modeling, fields of 100-1000 $\mu \mathrm{T}$ will exist in the convergence zone near the antipode of impact basins. As this magnetic field balances the plasma pressure, the size of the area affected by these maximum fields depends on the intensity of the original ambient field. For example, under simplifying assumptions, a $\sim 30 \mathrm{~km}$ radius for the area was estimated by the above authors if the ambient field was an early solar wind field, and a $\sim 140 \mathrm{~km}$ radius was estimated if the ambient field was a dynamo field with surface strength $10 \mu \mathrm{T}$. Among the studied samples, only 14053

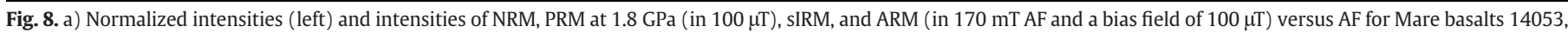

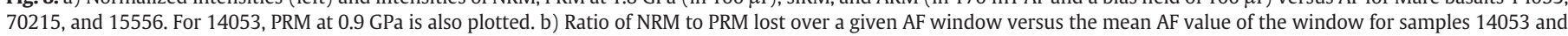
70215. PRM is scaled to an ambient field of $100 \mu \mathrm{T}$. The light (resp. dark) gray boxes indicate the directional stability interval of the NRM of 14053 (resp. 70215 ). 

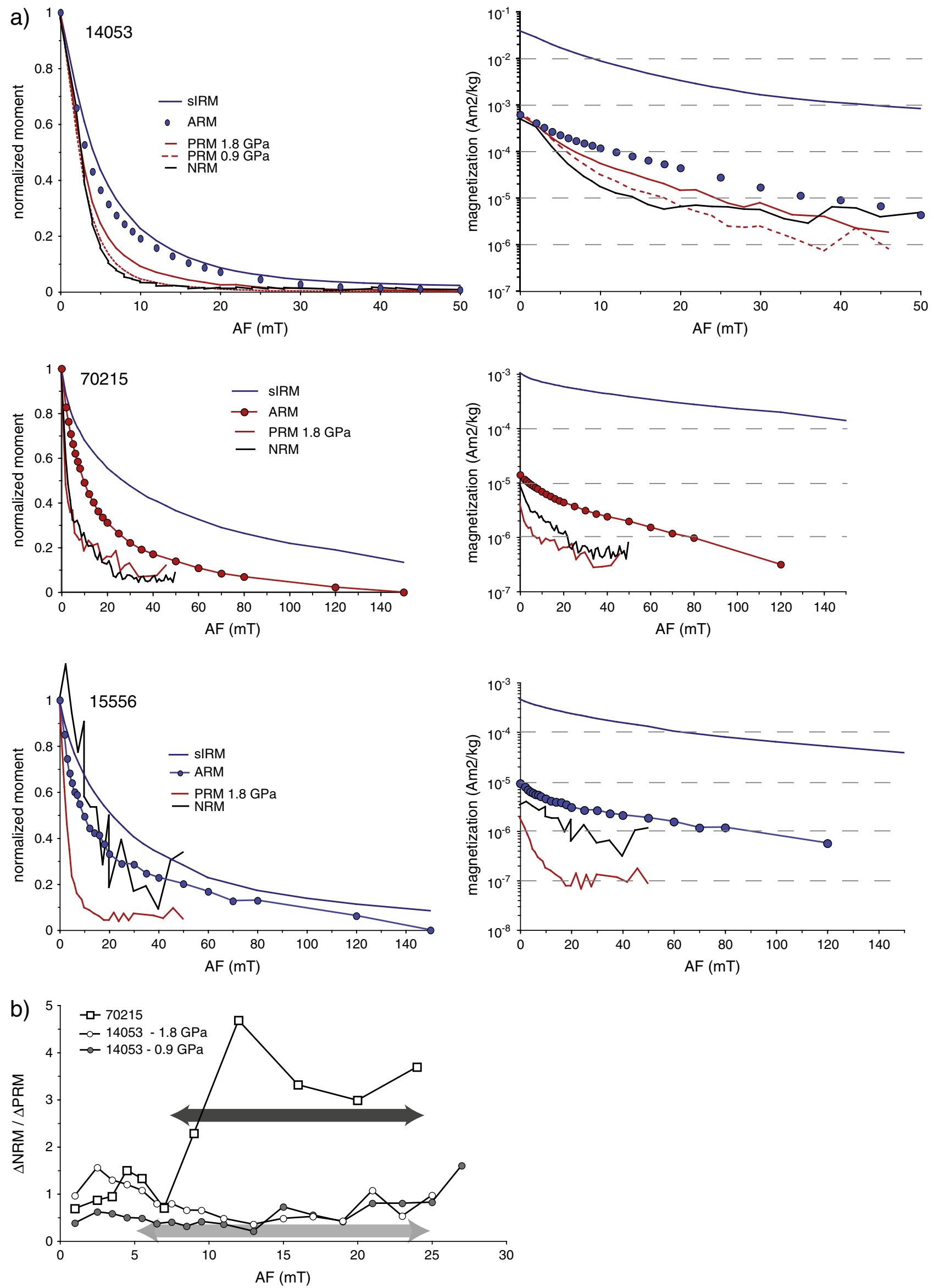
would be able to provide the necessary SRM intensity in a $100 \mu$ T field (conservative value for the maximum field in the antipodal area). Using our estimate for maximum SRM of typical lunar rocks (SRM/SIRM 1.2 $10^{-4} \mu \mathrm{T}^{-1}$, see above), a lunar rock can acquire a $1 \mathrm{~A} / \mathrm{m}$ magnetization during a low pressure shock ( $<10 \mathrm{GPa}$ ) in an ambient field of $100 \mu \mathrm{T}$ if it has a $\mathrm{M}_{\mathrm{rs}}>2.510^{-2} \mathrm{Am}^{2} \mathrm{~kg}^{-1}$. According to the review by Rochette et al. (2010) this condition ( $\log \mathrm{M}_{\mathrm{rs}}>1.4$ with $\mathrm{M}_{\mathrm{rs}}$ expressed in $10^{-3} \mathrm{Am}^{2} \mathrm{~kg}^{-1}$ ) is fulfilled by all Apollo and Luna soils, most Apollo regolith breccia, and by the highly magnetic sub-group of highland regolith and impact-melt breccia meteorites (such as Y 791197 feldspathic regolith breccia); whereas other Apollo breccias, Apollo Mare basalts, and all other meteorites fail to meet this condition. Considering that meteorites provide a representative sampling of the lunar upper crust, about $40 \%$ of lunar highland rocks fall in the highly magnetic group. Therefore, the SRM intensities determined experimentally in this work show that the antipodal anomaly model is plausible, especially if the magnetic anomalies are carried by regolith breccias and impact-processed highland rocks, a condition that is in agreement with the convergence of ejecta at the antipode of large impact basins. It is noteworthy that the largest group of strong antipodal magnetic anomalies (antipodal to Imbrium basin), is located on the edge of the older South-Pole Aitken basin where pre-Imbrium ejecta materials may be several km thick.

\section{Conclusion}

Shock experiments in controlled magnetic fields performed on lunar mare basalts demonstrated that in the presence of an ambient field these rocks can be magnetized significantly starting at low pressure $(\sim 0.1 \mathrm{GPa})$. Hydrostatic loading experiments up to $1.8 \mathrm{GPa}$ in controlled magnetic fields were used to impart piezo-remanent magnetization (an analogue to shock remanent magnetization) to mare basalts and highland regolith breccias. These experiments allow quantifying the shock remanence as a function of pressure and ambient field. The coercivity spectrum of SRM shifts towards higher coercivity values with increasing pressure. SRM increases linearly with the ambient field, and with peak pressure (a process that is limited by the availability of grains with high coercivity). For typical lunar rocks dominated by multidomain FeNi with low Ni content, we can propose a rough estimate of the maximum remanent magnetization that can be acquired during a low pressure shock ( $<10 \mathrm{GPa}$ ) as a function of $\mathrm{M}_{\mathrm{rs}}$ and the ambient field $\mathrm{B}$ (in $\mu \mathrm{T}$ ): $\mathrm{SRM}_{\max }=1.210^{-4} \times \mathrm{M}_{\mathrm{rs}} \times \mathrm{B}\left(\right.$ in $\left.\mathrm{Am}^{2} \mathrm{~kg}^{-1}\right)$, which is about a third of what is expected for a TRM acquired in the same ambient field. For sample 14053, that has a complex sub-solidus reduction history (Taylor et al., 2004) and magnetic remanence dominated by cohenite (this work), SRM is $6.710^{-4} \times \mathrm{M}_{\mathrm{rs}} \times \mathrm{B}$ (B in $\mu \mathrm{T}$, SRM in $\mathrm{Am}^{2} \mathrm{~kg}^{-1}$ ), i.e. more than 5 times stronger than in other lunar rocks. Also, SRM and TRM have about the same efficiency for 14053. This enhanced efficiency of shock magnetization with respect to other lunar rocks can be attributed to a stronger pressure sensitivity of cohenite with respect to FeNi minerals, in agreement with a magnetic phase transition at lower pressure: 4.3-6.5 GPa in cohenite (Gao et al., 2008) versus 9-13 GPa for FeNi alloys (Wasilewski, 1976).

Mare basalts 14053 and 70215, that have a stable NRM and reliable SRM data, have similar NRM and SRM coercivity spectra, leaving open the possibility that the NRM was imparted during an impact at the lunar surface. In that case, magnetizing fields of the order of 40 to $95 \mu \mathrm{T}$ are requested, which would be in the very upper range for a putative core dynamo field. Conversely, the NRM of mare basalt 15556 is not compatible with a SRM, which may imply it is a TRM and therefore require a long standing stable magnetic field (namely a dynamo generated field) whose intensity can be estimated to about $55 \mu \mathrm{T}$ using the REM' method. However, because the paleomagnetic data for this low coercivity rock are particularly noisy, this result cannot be taken as a proof of the existence of a former dynamo on the Moon, but is an incentive for additional paleomagnetic work on this sample.
In conclusion, SRM acquisition and AF demagnetization experiments appear necessary to ground the interpretation of lunar paleomagnetism. This is especially true because shocks below $5 \mathrm{GPa}$ are not discernible using standard petrological criteria. Even though the comparison of the coercivity spectra of NRM and different types of magnetization (TRM, SRM, Viscous remanent magnetization etc.) is not unique because the natural case may be more complex with superimposition of different phenomena (such as partial shock demagnetization of a TRM, or viscous demagnetization of a SRM), SRM experiments should become a standard technique in lunar and extraterrestrial paleomagnetism.

Regarding the lunar antipodal magnetic anomaly model, our results show that lunar soils, regolith breccia and about $40 \%$ of lunar highland rocks (comprising regolith and impact-melt breccia) in the upper crust can be magnetized by low pressure shocks ( $<10 \mathrm{GPa})$ to sufficient levels to account for the observed lunar antipodal anomalies, provided that the compressed ambient field in the antipodal region reaches about $100 \mu \mathrm{T}$ as proposed by Hood and Artemieva (2008). Therefore, the antipodal magnetization model appears to be plausible based on our experimental results, provided that several $\mathrm{km}$ of regolithized and impact-processed rocks can be found at the antipodes of large impact basins. These experimental results now allow further numerical modeling of the antipodal magnetization theory including combined pressure and magnetic field modeling.

\section{Acknowledgments}

The original manuscript benefited from very careful and constructive reviews by C.L. Johnson, and S. Gilder. This work was supported by the French Programme National de Planétologie (CNES-INSU).

\section{References}

Arkani-Hamed, J., 2005. Magnetic crust of Mars. J. Geophys. Res. 110. doi:10.1029/ 2004JE002397.

Bezaeva, N.S., Gattacceca, J., Rochette, P., Sadykov, R.A., Trukhin, I., 2010. Demagnetization of terrestrial and extraterrestrial rocks under hydrostatic pressure up to $1.2 \mathrm{GPa}$. Phys. Earth Planet Interiors 179, 7-20.

Butler, R.F., 1972. Natural remanent magnetization and thermomagnetic properties of the Allende meteorite. Earth Planet. Sci. Lett. 17, 120-128.

Cisowski, S.M., Collinson, D.W., Runcorn, S.K., Stephenson, A., 1983. A review of lunar paleointensity data and implications for the origin of lunar magnetism. J. Geophys. Res. 88 (suppl), A691-A704.

Collinson, D.W., 1993. Magnetism of the Moon - a lunar core dynamo or impact magnetization? Surv. Geophys. 14, 89-118.

Collinson, D.W., Runcorn, S.K., Stephenson, A., Manson, A.J., 1972. Magnetic properties of Apollo 14 rocks and fines, Third Lunar Science Conference. Geochim. Cosmochim. Acta, suppl. 3, 2343-2361.

Crawford, D.A., Schultz, P.H., 1988. Laboratory observations of impact-generated magnetic fields. Nature 336, 50-52.

Dickinson, T.L., Wasilewski, P.J., 2000. Shock magnetism in fine particle iron. Meteorit Planet. Sci. 35, 65-74.

Dunn, J.R., Fuller, M., 1972. On the remanent magnetism of lunar samples with special reference to 10048,55 and 14053,48 . Third lunar Science Conference: Geochim Cosmochim. Acta, 3, pp. 2363-2386.

Dyal, P., Packer, C.W., Sonett, C.P., 1970. Apollo 12 magnetometer: measurement of a steady magnetic field on the surface of the Moon. Science 169, 762-764.

El Goresy, A., Ramdohr, P., 1975. Subsolidus reduction of lunar opaque oxides: evidence, assemblages, geochemical relevance, and evidence for a late stage reducing gaseous mixture. Abstr. Lunar Planet. Sci. Conf. 6, 245.

Fuller, M., 1998. Lunar magnetism - a retrospective view of the Apollo sample magnetic studies. Phys. Chem. Earth 23, 725-735.

Fuller, M., Cisowski, S., 1987. Lunar paleomagnetism. In: Jacobs, J. (Ed.), Geomagnetism, vol. 2. Academic Press, Orlando, pp. 307-456.

Fuller, M., Rose, F., Wasilewski, P.J., 1974. Preliminary results of an experimental sudy of the magnetic effects of shocking lunar soil. The Moon 9, 57-61.

Funaki, M., Syono, Y., 2008. Acquisition of shock remanent magnetization for demagnetized samples in a weak field $(7 \mu \mathrm{T})$ by shock pressures 5-20 GPa without plasma-induced magnetization. Meteortitics Planet. Sci. 43, 529-540.

Gao, L.L., Chen, B., Wang, J.Y., Alp, E.E., Zhao, J.Y., Lerche, M., Sturhahn, W., Scott, H.P., Huang, F., Ding, Y., Sinogeikin, S.V., Lundstrom, C.C., Bass, J.D., Li, J., 2008. Pressure-induced 
magnetic transition and sound velocities of Fe3C: implications for carbon in the Earth's inner core. Geophys. Res. Lett. 35, L17306.

Garrick-Bethell, I., Weiss, B.P., Shuster, D.L., Buz, J., 2009. Early lunar magnetism. Science 323, 356-359.

Gattacceca, J., Rochette, P., 2004. Toward a robust normalized magnetic paleointensity method applied to meteorites. Earth Planet. Sci. Lett. 227, 377-393.

Gattacceca, J., Boustie, M., Weiss, B.P., Rochette, P., Lima, E., Fong, L.E., Baudenbacher, F. 2006. Investigating impact demagnetization through laser impacts and SQUID microscopy. Geology 34, 333-336.

Gattacceca, J., Lamali, A., Rochette, P., Boustie, M., Berthe, L., 2007. The effects of explosive-driven shocks on the natural remanent magnetization and the magnetic properties of rocks. Phys. Earth Planet. Inter. 162, 85-98.

Gattacceca, J., Berthe, L., Boustie, M., Vadeboin, F., Rochette, P., De Resseguier, T., 2008. On the efficiency of shock magnetization processes. Phys. Earth Planet. Inter. 166, 1-10.

Gattacceca, J., Boustie, M., Lima, E.A., Weiss, B.P., de Resseguier, T., Cuq-Lelandais, J.-P., 2010. Unraveling the simultaneous shock magnetization and demagnetization of rocks. Phys. Earth Planet. Interiors 182, 42-49.

Gilder, S.A., Le Goff, M., 2008. Systematic pressure enhancement of titanomagnetite magnetization. Geophys. Res. Lett. 35. doi:10.1029/2008GL033325.

Halekas, J.S., Mitchell, D.L., Lin, R.P., Hood, L.L., Acuña, M.H., Bonder, A.B., 2002 Demagnetization signatures of lunar impact craters. Geophys. Res. Lett. 29. doi:10.1029/2001GL013924.

Halekas, J.S., Lin, R.P., Mitchell, D.L., 2003. Magnetic fields of lunar multi-ring impact basins. Meteorit. Planet. Sci. 38, 565-578.

Hargraves, R.B., Dorety, A., 1975. Remanent magnetism in two Apollo 16 and two Apollo 17 rock sample. Lunar Science VI. The lunar science institute, Houston, p. 331.

Hood, L.L., 1987. Magnetic field and remanent magnetization effects of basin forming impacts on the Moon. Geophys. Res. Lett. 14, 844-847.

Hood, L.L., in press. Central magnetic anomalies of Nectarian-aged lunar impact basins: possible evidence for an early core dynamo. Icarus. doi:10.1016/j.icarus.2010.08.012.

Hood, L.L., Artemieva, N.A., 2008. Antipodal effects of lunar basin-forming impacts: initial 3D simulations and comparisons with observations. Icarus 193, 485-502.

Hood, L.L., Huang, Z., 1991. Formation of magnetic anomalies antipodal to lunar impact basins: two-dimensional model calculations. J. Geophys. Res. 96, 9837-9846.

Kirschvink, J.L., 1980. The least-squares line and plane and the analysis of palaeomagnetic data. Geophys. J. Int. 62, 699-718.

Langlais, B., Lesur, V., Purucker, M.E., Connerney, J.E.P., Mandea, M., 2010. Crustal magnetic fields of terrestrial planets. Space Sci. Rev.. doi:10.1007/s11214-0099557-y

Lawrence, K., Johnson, C., Tauxe, L., Gee, J., 2008. Lunar paleointensity measurements: Implications for lunar magnetic evolution. Phys. Earth Planet. Inter. 168, 71-877.

Louzada, K.L., Stewart, S.T., 2009. Effects of planet curvature and crust on the shock pressure field around impact basins. Geophys. Res. Lett. 36. doi:10.1029/ 2009GL037869.

Louzada, K.L., Stewart, S.T., Weiss, B.P., Gattacceca, J., Bezaeva, N.S., 2010. Shock and static pressure demagnetization of pyrrhotite and implications for the Martian crust. Earth Planet. Sci. Lett. 290, 90-101.
Martin, R.J., Noel, J.S., 1988. The influence of stress path on thermoremanent magnetization. Geophys. Res. Lett. 15, 507-510.

Mitchell, D.L., Halekas, J., Lin, R.P., Frey, S., Hood, L.L., Acuña, M.H., Binder, A.B., 2008. Global mapping of lunar crustal magnetic fields by Lunar Prospector. Icarus 194, 401-409.

Nagata, T., 1966. Main characteristics of piezo-magnetization and their qualitative interpretation. J. Geomag. Geoelec. 18, 81-97.

Nagata, T., Fisher, R.M., Schwerer, F.C., 1972. Lunar rock magnetism. The Moon 4, 170-196.

Pohl, J. Eckstaller, A 1981. The effect of shock on remanence in multi-domain iron grains and implications for palaeointensity measurements. Lunar and Planetary Science XII, 851-853 abstract.

Pohl, J., Bleil, U., Hornemann, U., 1975. Shock magnetization and demagnetization of basalt by transient stress up to 10 kbar. J. Geophys. 41, 23-41.

Richmond, N.C., Hood, L.L., 2008. A preliminary global map of the vector lunar crustal magnetic field based on Lunar Prospector magnetometer data. J. Geophys. Res. 113, E02010. doi:10.1029/2007JE002933.

Rochette, P., Gattacceca, J., Ivanov, A.V., Nazarov, M.A., Bezaeva, N.S., 2010. Magnetic properties of lunar materials: meteorites, Luna and Apollo returned samples. Earth Planet. Sci. Lett. 292, 383-391.

Sadykov, R., Bezaeva, N., Kharkovskiy, A.I., Rochette, P., Gattacceca, J., Trukhin, V.I., 2008. Non magnetic high pressure cell for magnetic remanence measurements up to 1.5 GPa in a superconducting quantum interference device magnetometer. Rev. Sci. Instrum. 79 (115102). doi:10.1063/1.2999578.

Stephenson, A., Collinson, D.W., 1974. Lunar magnetic field palaeointensities determined by an anhysteretic remanent magnetization method. Earth Planet. Sci. Lett. 23, 220-228.

Stephenson, A., Collinson, D.W., Runcorn, S.K., 1974. Lunar magnetic field paleointensity determinations on Apollo 11, 16, and 17 rocks. Fifth Lunar Conference: Geochim. Cosmochim. Acta suppl., 3, pp. 2859-2871.

Stöffler, D., Keil, K., Scott, E.R.D., 1991. Shock metamorphism of ordinary chondrites. Geochim. Cosmochim. Acta 55, 3845-3867.

Taylor, L.A., Patchen, A., Mayne, R.G., Taylor, D.H., 2004. The most reduced rock from the moon, Apollo 14 basalt 14053: its unique features and their origin. Amer. Miner. 89, 1617-1624.

Tikoo, S.M., Weiss, B.P., Buz, J., Garrick-Bethell, I., Grove, L., Gattacceca, J., 2010. Ancient lunar dynamo: absence of evidence is not the evidence of absence. $41^{\text {st }}$ Lunar Planetary Sci. Conf. abstract \#2705.

Walton, D., Shaw, J., Hakes, J., 1991. Microwave demagnetization. J. Appl. Phys. 71, 1549-1551.

Wasilewski, P., 1976. Shock loading meteorite bcc metal above the pressure transition: remanent magnetization stability and microstructure. Phys. Earth Planet Inter. 11, 5-11.

Wieczorek, M.A., Weiss, B.P., 2010. Testing the lunar dynamo hypothesis using global magnetic field data. $41^{\text {st }}$ Lunar and Planetary Science Conference. abstract \#1625.

Wieczorek, M.A., et al., 2006. The constitution and structure of the lunar interior. Reviews in Mineralogy \& Geochemistry 60, 221-364. 